\title{
Energy contagion analysis: A new perspective with application to a small petroleum economy
}

\author{
Scott M. R. Mahadeo ${ }^{\mathrm{a}, *}$, Reinhold Heinlein ${ }^{\mathrm{a}}$, Gabriella D. Legrenzi ${ }^{\mathrm{a}, \mathrm{b}, \mathrm{c}}$ \\ ${ }^{a}$ Keele Management School, Keele University, ST5 5BG, United Kingdom \\ ${ }^{b}$ CESifo Research Network \\ ${ }^{c}$ Rimini Centre for Economic Analysis
}

\begin{abstract}
We put forward the novel concept of energy contagion, i.e. a deepening of energy-finance linkages under crisis conditions in energy markets. Further, we show how to construct tests for energy contagion through correlation, co-skewness, and co-volatility channels. The samples of our contagion measures are defined in terms of calm and crisis periods in the international crude oil market. In particular, we compare how these various co-moments in the energy-finance nexus change during: (1) Oil booms and slumps using semi-parametric rule-based algorithms; (2) Tranquil and turbulent oil price volatility episodes using a non-hierarchical k-means clustering algorithm. Energy contagion analysis is essential to financial stability analysis in economies where prosperity is linked to the prices of hard commodities. Our applications are performed on the oil-exchange rate and oil-stock market relationships of the small petroleum economy of Trinidad and Tobago. The main results show a negative oil-real effective exchange rate dependency; a weak oil-stock returns association; and the existence of several energy contagion channels in both financial relationships, which are sensitive to the contemporary global financial crash.
\end{abstract}

Keywords: contagion; correlation; exchange rate; oil price; stock market; Trinidad and Tobago

JEL classification: C58; Q49

\section{Introduction}

Recently, contagion analysis has been gaining traction in the energy-finance nexus, especially in areas considering the spillover effects from oil prices to exchange rates (Reboredo et al., 2014; Baruník and Kočenda, 2018) and stock markets (Wen et al., 2012; Ding et al., 2017). Yet, this literature places the emphasis on comparing energy-financial markets relationships in and out of financial crisis time periods. While financial contagion tests tends to be based on a set financial crisis timespan ${ }^{1}$, we propose constructing energy contagion tests by comparing financial correlations

\footnotetext{
${ }^{*}$ Corresponding author's e-mail: s.m.r.mahadeo@keele.ac.uk

${ }^{1}$ For example, the National Bureau of Economic Research defines the timespan of contemporary Global Financial Crisis from December 2007 to June 2009. See www.nber.org/cycles, accessed in August 2018.
} 
during relatively calm and chaotic energy market conditions. We define energy contagion as a deepening of energyfinance linkages under crisis periods in energy markets. In particular, we consider crude oil market contagion because the connections between oil and other financial assets have recently deepened (Serletis and Xu, 2018), likely due to the leftover spillover effects from the recent Global Financial Crisis (GFC) (Wen et al., 2012). There is also a growing concern about the increasing financialisation of oil (Zhang and Broadstock, 2018).

Further, we make a contribution to empirical methods in energy economics by modifying the calm and crisis sample conditions of recently proposed contagion measures to test for energy, rather than financial, contagion. For this purpose, we take two approaches to identify discrete good and bad episodes in the international crude oil market. One is based on detecting oil booms and slumps proxied by bull and bear states, respectively, using semi-parametric rule-based algorithms. There are relatively few applications on detecting bull/bear phases in crude oil markets (see for example, Chang et al. (2010), Ntantamis and Zhou (2015), and Gil-Alana et al. (2016)). Yet, such an approach resonates well with the empirical oil studies which advocate that positive and negative oil price movements have asymmetric effects on the rest of the economy ${ }^{2}$. Our second approach employs a non-hierarchical k-means clustering algorithm to categorise realised crude oil market volatility measures into discrete groups of relative tranquillity and turbulence. The importance of the oil price volatility channel is also well established (see for example, Lee et al. (1995); Elder and Serletis (2011); Baumeister and Peersman (2013)). Indeed, hard commodities are the most volatile class of financial assets due to the high inventory costs and risk of shortages, which tend to prolong, compared to the quicker markets adjustments that occur for bonds, equities, and currencies (Downey, 2009).

We can then compare the oil-finance relationships under the calm and crisis oil market conditions identified. Correlation, co-skewness, and co-volatility contagion tests are used to construct energy contagion hypothesis testing across important co-moment transmission channels between crude oil and financial markets. For instance, co-skewness contagion can be observed for any pair of markets in two possible ways: Either, the mean behaviour of one market affecting the volatility of another; or, the volatility of one market affecting the mean behaviour of another (Fry et al., 2010). These two asymmetric dependence channels have the potential to identify additional linkages between markets with implications in the energy-finance nexus. Looking at how oil price volatility affects the performance of average financial returns, little research has been conducted in this area despite the repercussions commodity price volatility has for asset prices through production costs and investment decisions (Diaz et al., 2016). Likewise, a clear understanding of the relationship between crude oil prices and asset volatility is essential for formulating economic, energy, and financial policy in order to mitigate associated risks (Bastianin et al., 2016). Considering the co-volatility channel, which identifies contagion between second moments of two markets (Fry-McKibbin et al., 2014), such a perspective is relevant as twenty-first century commodity prices are hallmarked with exceptional volatility and commodity-equity market linkages have deepened in the GFC aftermath (Creti et al., 2013).

\footnotetext{
${ }^{2}$ The seminal works on testing the effects of non-linear oil price censoring specifications on the economy include Mork (1989) and Hamilton $(1996,2003)$
} 
Energy contagion analysis is potentially important for small extractive resource economies, which have real and financial sectors that are heavily exposed to shocks from international hard commodity markets. Indeed, the propagation of oil prices are more consequential for small open economies than larger ones (Abeysinghe, 2001) and, on average, small resource-endowed countries have a history of underperformance compared with their larger resourcerich equivalents (Auty, 2017). Our study focuses on links between the international crude oil market and the financial markets of the small open petroleum economy of Trinidad and Tobago, to evaluate whether we are able to diagnose energy contagion in such an environment. Testing a new concept is often done on relatively extreme cases. From this perspective, Trinidad and Tobago is an appropriate case as hydrocarbon assets have been extracted for over a century on the twin-island (Gelb, 1988). However, this country's legacy of monetising its sub-soil assets fosters a deep rooted energy dependency syndrome, with projected depletion before 2030 (Auty, 2017). In the twenty-first century, due in part to the pronounced fluctuations in international energy prices, the petroleum sector contribution to total output has been a roller-coaster: $28 \%$ in $2001,47 \%$ in $2006,45 \%$ in 2011 , and $19 \%$ in $2016^{3}$. The latest current account data convey an energy export to total export ratio of 78\%; while revised estimates show that $21 \%$ of government revenue in the fiscal year 2016/2017 derives from the energy sector, down from 48\% in the fiscal year 2013/2014 .

We are the first to explicitly evaluate the spillover effects international oil prices have on the financial markets of Trinidad and Tobago. Yet, our approach to energy contagion testing can be similarly applied for systemic risk analysis in any country whose fate is tied to the international prices of a hard commodity. Our empirical applications address two inter-related research questions: Do crisis episodes in the international crude oil market deepen the linkages in the energy-finance nexus in Trinidad and Tobago? If so, can higher co-moment channels provide further insights in such contagion scenarios? We find that the co-skewness and co-volatility dependence tests are able to detect additional channels of energy contagion not identified by the adjusted linear correlation test. However, our robustness analysis shows that such evidence is GFC-driven and we even observe reverse contagion in the oil-exchange rate relationship. Energy contagion in Trinidad and Tobago is subdued, likely due to country-specific characteristics: a dirty floating exchange rate and an embryonic stock market.

The rest of the paper is organised as follows. In Section 2 we examine the literature on the oil-exchange rate and oil-stock market relationships, and review studies on contagion testing in the oil-financial market nexus. Then, in Section 3, we explain our empirical procedures by specifying the contagion tests used and how they are augmented to test for energy contagion. In Section 4, we describe our data and procedures for adjusting our return series. Subsequently, we present the results in Section 5, provide policy implications in Section 6, and conclude in Section 7.

\footnotetext{
${ }^{3}$ These statistics are based on our own calculations using Central Bank of Trinidad and Tobago data. Available at www.central-bank.org.tt and retrieved in September 2018.

${ }^{4}$ These statistics are based on our own calculations using data in CBTT (2018).
} 


\section{The energy-finance nexus: Relationships and contagion analysis}

\subsection{Oil price-exchange rate relationship}

70 The effect of oil prices on the exchange rate typically depends on the net energy exporting status of a country (Reboredo et al., 2014; Turhan et al., 2014; Basher et al., 2016). Furthermore, the crude oil-exchange rate relationship is typically more pronounced in oil-exporting countries than in their oil-importing counterparts (Reboredo, 2012; Yang et al., 2017). Petrocurrencies tend to appreciate when oil prices are rising and depreciate when they decline (Bjørnland, 2004). This occurs due to the positive (negative) wealth effects channel in oil-exporting countries: higher (lower) oil income generated from oil price booms (slumps) stimulate (inhibit) economic activity, putting upward (downward) pressures on domestic prices, causing the exchange rate to appreciate (depreciate) (Bjørnland, 2009). Corden (1984, 2012) provides a related explanation for exchange rate appreciations in oil-exporting economies with the Dutch disease $^{5}$ theory; where commodity boom-induced revenues stimulate import expenditure, and increase wages and prices on the domestic market. This is called the spending effect and, akin to the wealth effect, it causes domestic inflation and currency appreciation which reduces the export competitiveness of non-booming commodities. Korhonen and Juurikkala (2009) use data from 1975 to 2005 in pooled mean group and mean group estimators, and find supporting evidence of appreciating exchange rates in response to higher oil prices in OPEC territories.

Because a dirty float has been the de facto exchange rate regime in Trinidad and Tobago since April 1993, with a stabilisation arrangement which anchors the Trinidad and Tobago dollar to the US dollar (Samuel and Viseth, 2018), the oil-exchange rate relationship in the US is important to consider. The US economy is peculiar as it is a large net oil-importer albeit major oil-producer. Furthermore, in global markets, crude oil is commonly invoiced and traded in US dollars (Reboredo, 2012). The long run and forecasting results of Lizardo and Mollick (2010) suggests a depreciation of the US dollar against the currencies of net oil-exporters when oil prices increase. If this currency depreciates (appreciates) then crude oil becomes cheaper (more expensive) for non-US consumers, which increases (decreases) their demand for crude oil, placing upward (downward) pressures on the price in this hard commodity market (Reboredo et al., 2014). Additionally, Ghosh (2011) and Lizardo and Mollick (2010) find the currencies of selected net oil-importers depreciate against the US dollar when oil prices increase.

However, the aforementioned dichotomous perspective on how oil prices affect oil-exporters and importers is not a consensus. In the case of the small open petroleum-exporting economy of Norway, mixed results are observed. Using a structural VAR model, Bjørnland (2004) finds that the real exchange rate depreciates in the first six months following an oil price shock and becomes insignificant thereafter, due to the slow response of the domestic price level relative to the immediate reaction of foreign prices. Also, Bjørnland (2009) uses a recursive VAR model with data on oil prices and the real, monetary, and financial sectors and finds a minimal appreciation of the real exchange rate,

\footnotetext{
${ }^{5}$ The name "Dutch" disease was coined in the 1970 s to describe the noteworthy demise of several manufacturing industries in the net energyexporting Netherlands, coinciding with the oil price boom of 1973/4.
} 
concluding that this unresponsiveness of the exchange rate to oil price shocks appear to be why Norway benefits from oil price increases. In light of the Norwegian peculiarity, we seek to understand the oil-exchange rate relationship in the small open petroleum economy of Trinidad and Tobago to unearth whether this is a case of conformity or also an anomaly.

\subsection{Oil price-stock market relationship}

Economists, investors, and policy makers are increasingly focusing on the correlation between oil and stock markets (Wen et al., 2012). Composite stock market indicators can be used as a barometer for macroeconomic performance, making it possible to proxy the impact of oil prices on the economy with the oil-stock market relationship (Ding et al., 2017). This is a reasonable point of view given that oil is a fundamental factor of production which affects the costing, cash flow, and expected returns on investments of firms, which are all determinants of stock returns (JiménezRodríguez, 2015; Diaz et al., 2016). Assuming both crude oil and stock markets are efficient, then these assets should be, on average, contemporaneously correlated (Huang et al., 1996). Indeed, stock markets quickly make use of all information available to them inclusive of the developments in oil prices (Bjørnland, 2009), especially in countries where the importance of oil to the macroeconomy is high (Wang et al., 2013).

The empirical literature shows that the nature of the oil-stock market relationship is context specific, since this association is sensitive to the type of industry (Gogineni, 2010) and country in question. Focusing on the latter, the results of Jones and Kaul (1996), Sadorsky (1999), and Papapetrou (2001) show that oil price shocks adversely affect the stock markets of selected developed countries. On the other hand, Aloui et al. (2013) employs a time-varying copula approach and infers that advanced-emerging and emerging Central and Eastern European countries exhibit a positive dependence between these two variables. Moreover, using structural VAR analysis, Wang et al. (2013) finds that the magnitude, duration, and direction of the stock market response to oil price shocks depend on the oil-exporting or oil-importing status of a country.

For oil-exporting economies, Bjørnland (2009) and Mohanty et al. (2011) show that rising oil prices typically have a stimulating effect on stock returns. However, Basher et al. (2018) find that while oil market shocks affect most oil-exporting countries, the sign and magnitude of oil market shocks are country specific. Interestingly, Basher et al. (2018) also observes that oil market shocks are not significant determinants of stock returns in Mexico and attributes this artefact to the possibility that this oil-exporting country has no large publicly traded petroleum companies. Therefore, it is important to consider whether the findings of Basher et al. (2018) on Mexico can be generalised for Trinidad and Tobago, as the first energy security was only listed on the Trinidad and Tobago Stock Exchange (TTSE) in October 2015 (TTSE, 2016). Within this context, we investigate how the stock market of this small emerging energy economy performs under good and bad crude oil market conditions. 


\subsection{Oil-financial market contagion testing}

Contagion is commonly defined as the deepening of cross-market co-movement after a shock occurs in one market (Forbes and Rigobon, 2002). Contagion has a tendency to appear and vanish quickly, relative to interdependence and cointegrating relationship which are inclined to endure (Reboredo et al., 2014). The applied work on contagion analysis in the energy-finance nexus focuses on how the relationship between commodity markets and financial assets might change during and in the aftermath of a financial crisis event, such as the GFC, when compared to pre-crisis era linkages.

Regarding the oil-exchange rate relationship, Reboredo (2012), Reboredo and Rivera-Castro (2013), and Reboredo et al. (2014) all use different methodologies, on the same dataset ${ }^{6}$, to examine the crude oil price-US dollar exchange rate dependency with respect to seven important currencies ${ }^{7}$ around the world and an aggregate exchange rate indicator, during pre-GFC and GFC periods. All three studies find consistent results. In particular, Reboredo (2012) employs standard correlation measures and a copula approach and observes that albeit the oil-exchange rate dependence is generally weak, these relationships deepen under crisis. In a similar spirit, Reboredo and Rivera-Castro (2013) use a wavelet multi-resolution decomposition approach and find no association in the pre-crisis sample but negative dependence in the crisis sample, suggestive of contagion effects in the latter period. Finally, Reboredo et al. (2014) apply detrended cross-correlation analysis, and find a weak negative oil price-exchange rate association which increases in the wake of the GFC, once again providing evidence for contagion.

Concerning contagion analysis in the crude oil-stock market connection, Guo et al. (2011) model the non-linear relationship between oil, stock, credit, and real estate markets in a four-dimensional Markov switching VAR for the US economy from October 2003 to March 2009. In the riskier of the two regimes they identify, which contains the GFC period, oil prices shocks drive stock market variability and the oil market is more responsive to stock market movements than the credit or real estate markets. In another study, Wen et al. (2012) use time-varying copulas to test for contagion between oil prices, and the US and Chinese stock markets. Additionally, they specify the dependence structures as an autoregressive model developed by Chiang et al. (2007), with a dummy variable to denote periods in and out of the GFC. In essence, the results of Wen et al. (2012) show a rise in the oil-stock market dependence structure during the GFC, indicative of contagion. However, they find this contagion effect is much stronger in the US compared to China.

Similar to our paper, Kayalar et al. (2017) considers the dependence structure between crude oil prices and both exchange rate and stock markets. Their analysis is applied to selected developed and emerging oil-exporting and importing countries. They use copula measures, as well as ARIMA and GARCH models, and find that both currency and equity markets exhibit stronger oil price dependency since the GFC. Kayalar et al. (2017) also note that both the

\footnotetext{
${ }^{6}$ Each consecutive study extends the GFC sample by a few months.

${ }^{7}$ The currencies included in these three studies are the Australian dollar, Canadian dollar, EU's euro, Japanese yen, Mexican peso, Norwegian krone, and UK's pound sterling.
} 
currency and stock markets of oil-exporters have a higher oil price dependency compared to oil-importers.

Contagion analysis also features in studies on commodity market interactions. For instance, Zhang and Broadstock (2018) estimate the dynamic connectedness between global commodity markets using a spillover index computed from the forecast error variance decomposition of a VAR system put forward in Diebold and Yilmaz $(2009,2014)$. Generally, Zhang and Broadstock (2018) observe that the co-dependence among commodity returns dramatically increases in the GFC aftermath and this continues to endure to the present. Focusing on their results as it relates to crude oil, Zhang and Broadstock (2018) find that even though this is the most volatile commodity class with one of the lowest average returns, oil prices show no strong integration with other commodities. On the other hand, Algieri and Leccadito (2017) use a delta conditional value-at-risk approach based on quantile regression and find that a distress occurring in the crude oil market has the largest negative consequences for the rest of the US economy when compared to food, metals, and other energy commodities. Yet, as no control is provided for the GFC, it is not possible to deduce if the inferences of Algieri and Leccadito (2017) are GFC driven.

Against this background, instead of defining the pre-crisis and crisis periods of contagion tests based on a financial crash, our paper contributes to the field by constructing the calm and crisis samples based on discrete slumping or booming phases and high or low volatility conditions in the international crude oil market. This approach is applied to correlation, co-skewness, and co-volatility contagion channels. Our methodology facilitates a straightforward, albeit comprehensive, diagnostic tests for the transmission of energy contagion from the international crude oil market to the financial markets of a petroleum economy. This perspective is especially useful for economies where the real and financial sectors are highly exposed to oil price disturbances.

\section{Methodology}

\subsection{Contagion analysis methods}

Correlation is the most widespread way of measuring the dependence structure between a pair of random variables (Reboredo, 2012). A straightforward way to test for contagion is to compare financial correlations in calm and crisis periods. If the magnitude of the relationship is notable and similar in both samples this is interdependence not contagion, as contagion is observed if market correlations deepen under crisis periods (Forbes and Rigobon, 2002). In addition, we define reverse contagion as strong correlation under calm periods which become significantly weaker, in absolute value, during crisis events. We first describe the standard correlation measures used to explore the relationship between oil and financial asset markets when the international crude oil market is in calm versus crisis periods: Pearson's $\rho$, Spearman's $\rho$, and Kendall's $\tau$. Then, we outline the correlation contagion tests which we will augment for our energy contagion analysis: the adjusted linear correlation, co-skewness, and co-volatility tests. 


\subsubsection{Correlation comparisons using Pearson's $\rho$, Spearman's $\rho$, and Kendall's $\tau$}

Pearson correlation is popular in financial contagion analysis for comparing dependence structures in calm and crisis periods (Inci et al., 2011; Li and Zhu, 2014). For any pair of variables, bivariate linear correlation is measured using the simple Pearson product-moment correlation coefficient (Pearson's $\rho$ ). This is computed as the covariance of the pair of variables divided by the product of their standard deviations. We estimate Pearson's $\rho$ to gain insights into how the dependence between oil and financial asset returns change under calm and crisis oil market conditions. However, as a measure of contagion, Pearson's $\rho$ has several shortcomings: It is ill-suited for non-linear dependence; the coefficient can vary based on monotonic transformations ${ }^{8}$; and it is symmetric and cannot distinguish between associations during market ups and downs, or between large and small movements, and assumes homoskedasticity (see Reboredo (2012) and references therein).

Consequentially, we follow Reboredo (2012) and use the Spearman and Kendall rank correlation coefficients as alternative measures of correlation to be used in conjunction with Pearson's $\rho$. These are also computed to obtain the energy-finance correlations during calm and crisis oil market samples. Both Spearman's $\rho$ and Kendall's $\tau$ are measures of ordinal association, which are determined based on the degree of similarity between the rankings of two variables. By using rankings instead of observation values, these rank correlation coefficients are more robust to outliers than Pearson's $\rho$ (Abdullah, 1990), since the latter is computed from the sample means of the market returns. Such non-parametric dependence measures are particularly attractive in the analysis of financial markets prone to conditions of extreme values.

\subsubsection{Adjusted linear correlation contagion test}

Given that Pearson's correlation coefficient spuriously increases with market volatility, Forbes and Rigobon (2002) propose a correction for this heteroskedasticity bias. Equation (1) shows a two-sided test statistic variant of the Forbes and Rigobon (2002) contagion test as suggested in Fry et al. (2010) and Fry-McKibbin et al. (2014), which is a significance test for a change in the adjusted crisis period correlation (i.e., $\hat{v}_{y \mid x_{i}}$ ) compared to the calm period correlation (i.e., $\hat{\rho}_{x}$ ) from the source market $i$ to the recipient market $j$. For our purposes, $i$ denotes international crude oil returns and $j$ indicates the returns of a financial market indicator (i.e., exchange rate or stock market returns) for a small oil-exporter (i.e., Trinidad and Tobago).

$$
C R_{\overline{F R}}(i \rightarrow j)=\left(\frac{\hat{v}_{y \mid x_{i}}-\hat{\rho}_{x}}{\sqrt{\operatorname{Var}\left(\hat{v}_{y \mid x_{i}}-\hat{\rho}_{x}\right)}}\right)^{2}
$$

where, under the null hypothesis of "no contagion", the test statistic is asymptomatically distributed as $C R_{\overline{F R}}(i \rightarrow$ j) $\stackrel{d}{\rightarrow} \chi_{1}^{2}$, and where the adjusted sample correlation coefficient, which permits for an increase in volatility in the crude oil market, is given in Equation (2):

\footnotetext{
${ }^{8}$ For example, correlation coefficient for returns and log returns are likely to be different for a pair of continuous random variables.
} 


$$
\hat{v}_{y \mid x_{i}}=\frac{\hat{\rho}_{y}}{\sqrt{1+\left(\left(s_{y, i}^{2}-s_{x, i}^{2}\right) / s_{x, i}^{2}\right)\left(1-\hat{\rho}_{y}^{2}\right)}}
$$

where $s_{x, i}^{2}$ and $s_{y, i}^{2}$ are the return variances in the international oil market $(i)$ in calm and crisis oil market periods, ${ }_{220}$ correspondingly; and where $\hat{\rho}_{x}$ in Equation (1) and $\hat{\rho}_{y}$ in Equation (2) are the oil-financial market Pearson correlation in the calm and crisis oil market condition samples, respectively. It is worth mentioning that the accuracy of the adjusted linear correlation test can be affected by omitted variables, as well as the degree of endogeneity between the markets. We address both of these issues in the data section.

\subsubsection{Co-skewness contagion tests}

Fry et al. (2010) take contagion analysis a step further and put forward two higher order co-moment contagion tests to ascertain whether there are statistically significant differences in calm and crisis market correlations based on changes in co-skewness, i.e. a shared higher-order (third) moment for a pair of continuous random variables. Co-skewness contagion can occur in one of two ways: Either, the mean behaviour of one market affecting the volatility of another as given by Equation (3); or, the volatility of one market affecting the mean behaviour of another as illustrated in Equation (4). Fry et al. (2010) show that this asymmetric dependence perspective is able to reveal additional channels of contagion, beyond the approach described by Forbes and Rigobon (2002). Further applications of these tests are covered in Fry-McKibbin et al. (2014) and Fry-McKibbin and Hsiao (2018). Equation (3) conveys the test statistic corresponding to the null hypothesis of no contagion spillover from average oil returns to the volatility of a financial asset market in Trinidad and Tobago:

$$
C S_{1}\left(i \rightarrow j ; r_{i}^{1}, r_{j}^{2}\right)=\left(\frac{\hat{\psi}_{y}\left(r_{i}^{1}, r_{j}^{2}\right)-\hat{\psi}_{x}\left(r_{i}^{1}, r_{j}^{2}\right)}{\sqrt{\left(4 \hat{v}_{y \mid x_{i}}^{2}+2\right) / T_{y}+\left(4 \hat{\rho}_{x}^{2}+2\right) / T_{x}}}\right)^{2}
$$

whereas, the test statistic denoted in Equation (4) is associated with the null hypothesis of no contagion spillover from oil market volatility to an average financial market returns in Trinidad and Tobago:

$$
C S_{2}\left(i \rightarrow j ; r_{i}^{2}, r_{j}^{1}\right)=\left(\frac{\hat{\psi}_{y}\left(r_{i}^{2}, r_{j}^{1}\right)-\hat{\psi}_{x}\left(r_{i}^{2}, r_{j}^{1}\right)}{\sqrt{\left(4 \hat{v}_{y \mid x_{i}}^{2}+2\right) / T_{y}+\left(4 \hat{\rho}_{x}^{2}+2\right) / T_{x}}}\right)^{2}
$$

where $r_{i}^{1}$ and $r_{i}^{2}$ are the mean and standard deviation of returns in the crude oil market, correspondingly, and $r_{j}^{1}$ and $r_{j}^{2}$ are the same for a given financial asset market in Trinidad and Tobago which can potentially be affected. Furthermore, $T_{x}$ and $T_{y}$ are defined as the calm and crisis oil market sample sizes, respectively, and $\hat{\rho}_{x}$ in Equations (3) and (4) is the conditional correlation estimate between crude oil and a given financial market in calm oil market conditions. Furthermore, $\hat{v}_{y \mid x_{i}}$ is a sample correlation coefficient which corrects the heteroskedasticity bias in the oil market crisis 230 period conditional on the volatility in the calm oil market period, as described earlier in Equation (2). Additionally, Equations (5) and (6) show the respective forms the standardisation parameters $\hat{\psi}_{x}\left(r_{i}^{m}, r_{j}^{n}\right)$ and $\hat{\psi}_{y}\left(r_{i}^{m}, r_{j}^{n}\right)$ take: 


$$
\begin{aligned}
& \hat{\psi}_{x}\left(r_{i}^{m}, r_{j}^{n}\right)=\frac{1}{T_{x}} \sum_{t=1}^{T_{x}}\left(\frac{x_{i, t}-\hat{\mu}_{x i}}{\hat{\sigma}_{x i}}\right)^{m}\left(\frac{x_{j, t}-\hat{\mu}_{x j}}{\hat{\sigma}_{x j}}\right)^{n} \\
& \hat{\psi}_{y}\left(r_{i}^{m}, r_{j}^{n}\right)=\frac{1}{T_{y}} \sum_{t=1}^{T_{y}}\left(\frac{y_{i, t}-\hat{\mu}_{y i}}{\hat{\sigma}_{y i}}\right)^{m}\left(\frac{y_{j, t}-\hat{\mu}_{y j}}{\hat{\sigma}_{y j}}\right)^{n}
\end{aligned}
$$

where $x$ reflects the calm and $y$ is the crisis oil market behaviours; $\hat{\mu}$ and $\hat{\sigma}$ are the mean and standard error, respectively, for a given market (i.e., $i$ or $j$ ) under a given sample (i.e., $x$ or $y$ ); and $r^{m}\left(r^{n}\right)$ is the average returns for market $\mathrm{i}(\mathrm{j})$ in the test version $C S_{1}\left(C S_{2}\right)$ and squared returns in the test version $C S_{2}\left(C S_{1}\right)$. The test statistics in Equations (3) and (4), when their associated null hypotheses are true, are asymptotically distributed as $C S(i \rightarrow j) \stackrel{d}{\rightarrow} \chi_{1}^{2}$.

\subsubsection{Co-volatility contagion test}

Fry-McKibbin et al. (2014) and Fry-McKibbin and Hsiao (2018) introduce an extremal dependence test based on changes in co-volatility. The test statistic for the transmission from market $i$ (i.e., the crude oil market) volatility to market $j$ (i.e., the exchange rate or stock market in Trinidad and Tobago) volatility is given in Equation (7).

$$
C V\left(i \rightarrow j ; r_{i}^{2}, r_{j}^{2}\right)=\left(\frac{\hat{\xi}_{y}\left(r_{i}^{2}, r_{j}^{2}\right)-\hat{\xi}_{x}\left(r_{i}^{2}, r_{j}^{2}\right)}{\sqrt{\left(4 \hat{v}_{y \mid x_{i}}^{4}+16 \hat{v}_{y \mid x_{i}}^{2}+4\right) / T_{y}+\left(4 \hat{\rho}_{x}^{4}+16 \hat{\rho}_{x}^{2}+4\right) / T_{x}}}\right)^{2}
$$

Once again, $\hat{v}_{y \mid x_{i}}$ enters into the computation to adjust for the heteroskedasticity bias in the oil market crisis period, and the standardisation parameters $\hat{\xi}_{x}\left(r_{i}^{2}, r_{j}^{2}\right)$ and $\hat{\xi}_{y}\left(r_{i}^{2}, r_{j}^{2}\right)$ take the form shown in Equations (8) and (9), respectively.

$$
\begin{aligned}
& \hat{\xi}_{x}\left(r_{i}^{2}, r_{j}^{2}\right)=\frac{1}{T_{x}} \sum_{t=1}^{T_{x}}\left(\frac{x_{i, t}-\hat{\mu}_{x i}}{\hat{\sigma}_{x i}}\right)^{2}\left(\frac{x_{j, t}-\hat{\mu}_{x j}}{\hat{\sigma}_{x j}}\right)^{2}-\left(1+2 \hat{\rho}_{x}^{2}\right) \\
& \hat{\xi}_{y}\left(r_{i}^{2}, r_{j}^{2}\right)=\frac{1}{T_{y}} \sum_{t=1}^{T_{y}}\left(\frac{y_{i, t}-\hat{\mu}_{y i}}{\hat{\sigma}_{y i}}\right)^{2}\left(\frac{y_{j, t}-\hat{\mu}_{y j}}{\hat{\sigma}_{y j}}\right)^{2}-\left(1+2 \hat{v}_{y \mid x_{i}}^{2}\right)
\end{aligned}
$$

and where all other notations are defined according to the previous contagion tests and under the null of "no contagion", the co-volatility test is also asymptotically distributed as $C V(i \rightarrow j) \stackrel{d}{\rightarrow} \chi_{1}^{2}$.

\subsection{Identifying calm and crisis energy market conditions}

Another original contribution of our paper is based on the identification strategy for the calm and crisis samples of the aforementioned contagion tests. We use booming/slumping and tranquil/turbulent volatility scenarios to proxy calm/crisis energy periods across our sample. 


\subsubsection{Bull/bear proxy for booming/slumping oil market phases}

As surrogates for oil booms (calm) and slumps (crisis) periods, we employ rule-based algorithms to identify bull and 250 bear crude oil market phases, respectively, following the approaches of Pagan and Sossounov (2003) and Lunde and Timmermann (2004). The phases in these two methods are determined by maxima and minima in crude oil prices, but vary in which of these extrema result in a state switch (see Kole and Dijk (2017) for a more thorough comparison).

\section{Pagan and Sossounov (2003) approach}

In this approach, bull and bear phases are identified based on the programmed determination of turning points outlined in Pagan and Sossounov (2003). This procedure applies rules such that a peak (trough) is based on whether the oil price in month $t$ is above (below) other months within the interval $t-\tau_{\text {window }}$ and $t+\tau_{\text {window }}$. As the maxima and minima that triggers the shifts between bull and bear phases, extrema values towards the end of the interval are prevented from distorting the identification of markets states, with a further rule $\tau_{\text {censor }}$. We follow Pagan and Sossounov (2003) and set $\tau_{\text {window }}=8$ months and $\tau_{\text {censor }}=6$ months. Gil-Alana et al. (2016) also adopts this calibration to identify bear and bull phases in the crude oil market. This yields a dummy variable with oil crisis (bear) and calm (bull) sample periods for our energy contagion test.

\section{Lunde and Timmermann (2004) approach}

Here, a shift in a market phase is determined by two threshold scalars: $\lambda_{1}$ and $\lambda_{2}$, where $\lambda_{1}\left(\lambda_{2}\right)$ activates a switch from a bear (bull) to a bull (bear) market. We follow a feasible combination suggested in Lunde and Timmermann (2004) and employed in Kole and Dijk (2017), and set $\lambda_{1}=0.20$, which indicates a minimum increase of $20 \%$ in the market index since the last trough will activate a switch from a bearish regime to a bullish regime, and $\lambda_{2}=0.15$, which provides a rule that a minimum decrease of $15 \%$ since the last peak is needed to activate a switch from a bull phase to a bear phase. For previous empirical work done on commodity markets, Ntantamis and Zhou (2015) use alternative $\lambda_{1}$ and $\lambda_{2}$ combinations marginally higher and lower than the standard thresholds we employ here and find no substantial difference in their results. Again, we acquire a dummy variable with discrete bear and bull phases for testing energy contagion.

\subsubsection{Tranquil and turbulent oil market volatility scenarios}

To determine tranquil (calm) and turbulent (crisis) crude oil market volatility samples, we first estimate two simple oil price volatility measures: A range estimator and realised monthly volatility. Then, we apply a non-hierarchical kmeans clustering algorithm to sort oil market volatility into two discrete groups of relatively lower (tranquil) and higher (turbulent) volatility periods. The clustering is based on Euclidean distance as the measure of similarity/dissimilarity in order to maximise between cluster variance and minimise within cluster variance of the two groupings.

\section{Oil price range estimator}

We augment the range estimator component of the high-low volatility method proposed in Parkinson (1980) to 280 compute the monthly average oil price range using daily maximum and minimum spot values, as Equation (10) shows. 


$$
\operatorname{range}_{t}^{O P}=\frac{1}{n} \sum_{\tau=1}^{n}\left(\ln \left(\frac{O P_{t, \tau}^{\max }}{O P_{t, \tau}^{\min }}\right)\right)
$$

where $\ln \left(O P_{t, \tau}^{\max } / O P_{t, \tau}^{\min }\right)$ is the log of the ratio of the highest to lowest observed oil prices for day $\tau$, and this range is averaged over a given month $t$ with $n$ as the amount of days crude oil was traded in that month. Next, using cluster analysis, we acquire a binary outcome of tranquil and turbulent sub-samples, as shown in Equation (11), for the energy contagion tests.

$$
\text { Dummy }_{t}^{\text {range }}= \begin{cases}1, & \text { if }\left[\text { range }_{t}^{O P}-c_{1}\right]^{2}<\left[\text { range }_{t}^{O P}-c_{0}\right]^{2} \\ 0, & \text { otherwise }\end{cases}
$$

where $c_{0}$ and $c_{1}$ are the centroids (i.e., the mean values) of tranquil and turbulent clusters, respectively, of the oil price range estimator.

\section{Realised monthly oil price volatility}

To analyse oil volatility, Mohaddes and Pesaran (2013) use an annualised variation of realised volatility commonly employed for calculating daily realised volatilities of financial returns. Here, we adopt a modified version of Mohaddes and Pesaran (2013) formula, in Equation (12). Since every month has a different amount of trading days, which will obviously impact the volatility summed in each month, we use daily volatility averaged over the month to circumvent this issue.

$$
r m v_{t}^{O P}=\sqrt{\frac{1}{n} \sum_{\tau=1}^{n}\left(\Delta \ln O P_{t, \tau}-\overline{\Delta \ln O P}_{t}\right)^{2}}
$$

where $r m v_{t}^{O P}$ is the realised monthly average volatility of seasonally adjusted real daily oil returns; $n$ is the amount of days crude oil was traded in a given month; $\Delta \ln O P_{t, \tau}$ is monthly oil returns for day $\tau$ in month $t$; and $\overline{\Delta \ln } O P_{t}=$ $\frac{1}{n} \sum_{t=1}^{n} \Delta \ln O P_{t, \tau}$, denoting the average daily oil returns during the month. Subsequently, we cluster oil market volatility into the binary outcome of tranquil and turbulent samples, as suggested by Equation (13).

$$
\text { Dummy }_{t}^{r m v}= \begin{cases}1, & \text { if }\left[r m v_{t}^{O P}-c_{1}\right]^{2}<\left[r m v_{t}^{O P}-c_{0}\right]^{2} \\ 0, & \text { otherwise }\end{cases}
$$

where $c_{0}$ and $c_{1}$ are the centroids of tranquil and turbulent clusters, respectively, of $r m v_{t}^{O P}$.

\section{Data}

Our data is monthly and spans January 1994 to August 2017 on oil prices, US interest rates, as well as exchange rates, interest rates, and stock returns for Trinidad and Tobago. Table A.5 provides the data definitions and sources. We use international crude oil prices as our energy market performance indicator. This is because oil remains the primary 
source of global energy consumption, i.e. $32.9 \%$, with no challenging substitutes threatening more than $5 \%$ of this share before 2020 (WEC, 2016). Also, although Trinidad and Tobago is an oil and gas economy, natural gas prices are often indexed to crude oil prices implying that most of the information contained in gas prices are already captured by oil prices (Zhang and Broadstock, 2018). The two most important global oil price benchmarks are the reference prices associated with the Brent and West Texas Intermediate (WTI) crude blends. Despite the fact that world crude oil prices trend together due to arbitrage (Reboredo, 2011), the WTI benchmark has departed from this co-movement between 2011 and 2014, trading at a discounted price. This is due to the US shale boom causing excess supply of light sweet crude in the central US market (Kilian, 2016). As such, we follow Baumeister and Kilian (2016a) and use Brent crude oil prices. Regarding the real price level per barrel of crude oil, an upward trend is noted from 2003 until mid 2008 in Figure 1, denoting the oil price boom of the 2000s. However, this commodity enters an era of uncertainty as real prices fell by 68\% between July 2008 and December 2008 and by 57\% from June 2014 to January 2015.

We use the Real Effective Exchange Rate (REER) of Trinidad and Tobago as our exchange rate indicator. The REER index has a straightforward interpretation: an increase implies exports have become relatively more expensive and imports cheaper, which indicates a reduction in the country's trade competitiveness. Figure 1 shows that from the start of the sample until the GFC, the REER exhibits a relatively gradual upward trend when compared to the more steep growth experienced in the post-GFC period. It is interesting to note that the appreciation in the REER index coincides with the aforementioned international oil price plummets. CBTT $(2009,2015)$ explains that these appreciations in the Trinidad and Tobago REER are indirectly tied, via the managed float, to the strengthening US dollar relative to other major currencies.

We use the Composite Stock Price Index (CSPI) compiled by the TTSE as the stock market performance indicator. The TTSE is just about 4 decades old and currently consists of First Tier, Second Tier, and Mutual Funds markets. We focus on the First Tier Market ${ }^{9}$, the most important group based on market capitalisation, which lists 31 securities classified under: banking, conglomerates, energy, property, manufacturing, trading, non-banking finance, and nonsector (TTSE, 2017). The CSPI is a market-value weighted index collectively measuring the price movement of the ordinary shares for companies listed on the First Tier Market. Figure 1 depicts a bullish trend in the real CSPI stretching from the latter half of 2003 to early months of 2005 that is interrupted by two corrections for overheating stock prices from the previous year. The first correction in March 2005 is due to the introduction of automated trading, and the second in May 2005 happens when registered pension plan equities sell down (TTSE, 2006). Furthermore, the subsequent wave of optimistic stock market behaviour in the first half of 2008 is supplanted by the GFC and remains relatively stagnant for the rest of the sample.

Real oil prices, the REER index, and real CSPI are all seasonally adjusted ${ }^{10}$ and expressed as returns, i.e. the first difference in the natural logarithm for each series, times 100. Subsequently, to remove lead-lag effects and serial

\footnotetext{
${ }^{9}$ The Second Tier and Mutual Funds markets of the TTSE lists only 1 and 5 securities, respectively.

${ }^{10}$ Seasonal adjustments are performed using the filtration procedure suggested in Cleveland et al. (1990), which is robust against aberrant time series behaviour, making it particularly appealing for seasonally decomposing financial variables punctuated by crises.
} 
correlation from the return series, we work with residuals $\left(\varepsilon_{t}\right)$ from Equations (14), (15), and (16), respectively, as our adjusted returns. The exogeneity of international oil prices for a small economy like Trinidad and Tobago drives our choice of specification for these regressions. Adjusted oil returns is acquired from the single equation model specified in Equation (14).

$$
\Delta \ln O P_{t}=\alpha_{0}+\alpha_{1} \Delta \ln O P_{t-1}+\alpha_{2} S S R_{t-1}+\varepsilon_{t}
$$

where $\Delta \ln O P_{t}$ are real Brent crude oil returns, $\alpha_{0}$ is a constant, $\Delta \ln O P_{t-1}$ is an autoregressive term, and $S S R_{t-1}$ are the US interest rates. An optimal lag order of 1 month is determined by information criteria and there is no residual autocorrelation based on a Lagrange multiplier test at the conventional levels of significance.

As neither exchange rates nor stock returns from Trinidad and Tobago can affect international crude oil returns, we use the residuals from Equations (15) and (16) from a VARX(1) system to obtain these adjusted financial returns.

$$
\begin{aligned}
& \Delta \ln R E E R_{t}=\alpha_{10}+\alpha_{11} \Delta \ln R E E R_{t-1}+\alpha_{12} \Delta \ln C S P I_{t-1}+\alpha_{13} I R_{t-1}+\alpha_{14} \Delta \ln O P_{t-1}+\alpha_{15} S S R_{t-1}+\varepsilon_{1 t} \\
& \Delta \ln C S P I_{t}=\alpha_{20}+\alpha_{21} \Delta \ln C S P I_{t-1}+\alpha_{22} \Delta \ln R E E R_{t-1}+\alpha_{23} I R_{t-1}+\alpha_{24} \Delta \ln O P_{t-1}+\alpha_{25} S S R_{t-1}+\varepsilon_{2 t}
\end{aligned}
$$

where $\Delta \ln R E E R_{t}$ is the growth rate of the REER, $\Delta \ln C S P I_{t}$ is real composite stock returns, $I R_{t-1}$ denotes domestic interest rate for Trinidad and Tobago, along with exogenous variables for oil returns $\left(\Delta \ln O P_{t-1}\right)$ and US interest rates $\left(S S R_{t-1}\right)$. An appropriate lag length of 1 month is selected using information criteria and a Lagrange multiplier test shows there is no statistically significant residual serial correlation.

Following Forbes and Rigobon (2002), interest rates are included in Equations (14), (15), and (16) to account for macroeconomic and monetary performance. This is because the correlation between asset returns might occur due to the omission of economic fundamentals and not because of contagion. We use US short term interest rates as a foreign economic activity measure for the following reasons. Crude oil is primarily invoiced in US dollars (Kayalar et al., 2017) and fluctuations in this currency may affect the behaviour of crude oil prices (Zhang et al., 2008). Furthermore, Kilian and Zhou (2018) finds that exogenous fluctuations in US real interest rates have quantitatively important effects on oil prices. These perspectives motivate accounting for the real sector and policy environment of the US in the oil returns model. Also, the USA is Trinidad and Tobago's major trading partner, in terms of both exports and imports, providing a rationale to include US interest rates in our models for adjusting exchange rate and stock returns as well. To these ends, we use US Shadow Short Rates (SSRs) ${ }^{11}$ as a foreign interest rate measure relevant to this small-island economy. US SSRs adjusts the conventional policy rate to accommodate for unconventional monetary authority actions, like quantitative easing, by permitting the rate to take on values below the zero lower bound.

We use the commercial banking median basic prime lending rate to proxy real, policy, and financial activity in Trinidad and Tobago. This interest rate is available for our entire sample and is highly positively correlated with other important monetary policy rates ${ }^{12}$ and also conveys financial sector specific information. Additionally, we allow

\footnotetext{
${ }^{11}$ See data appendix for further details.

${ }^{12}$ For example, the median prime lending rate and the 3 month treasury bill average discount rate has a Pearson's $\rho$ of 0.93 between $1995 \mathrm{~m} 1$ $2017 \mathrm{~m} 8$, and median prime lending rate and the Central Banks repo and discount rates from 2002m5-2017m8 have a Pearson's $\rho$ of 0.91 .
} 
exchange rate and stock returns to enter each other's regression functions endogenously to account for potential lead-

lag interactions. For instance, the flow-oriented model characterises the influence exchange rates can have on the stock market, while the portfolio balance approach establishes that stock prices affect exchange rates (see Chkili and Nguyen (2014) and references therein).

Figure 1 shows plots of the main time series variables used in our study: the monthly levels and adjusted returns for the three series, along with foreign (US) and domestic (Trinidad and Tobago) interest rates. The GFC period, i.e. $\quad 360$ from December 2007 to June 2009, is clearly marked on the graphs. It can be seen that the three adjusted returns (and their levels) have all been impacted by the GFC, as these assets all exhibit breaks coinciding with that time period. Hence, our sensitivity analysis involves comparing samples with and without this period to evaluate if the energy contagion results are robust to the GFC.
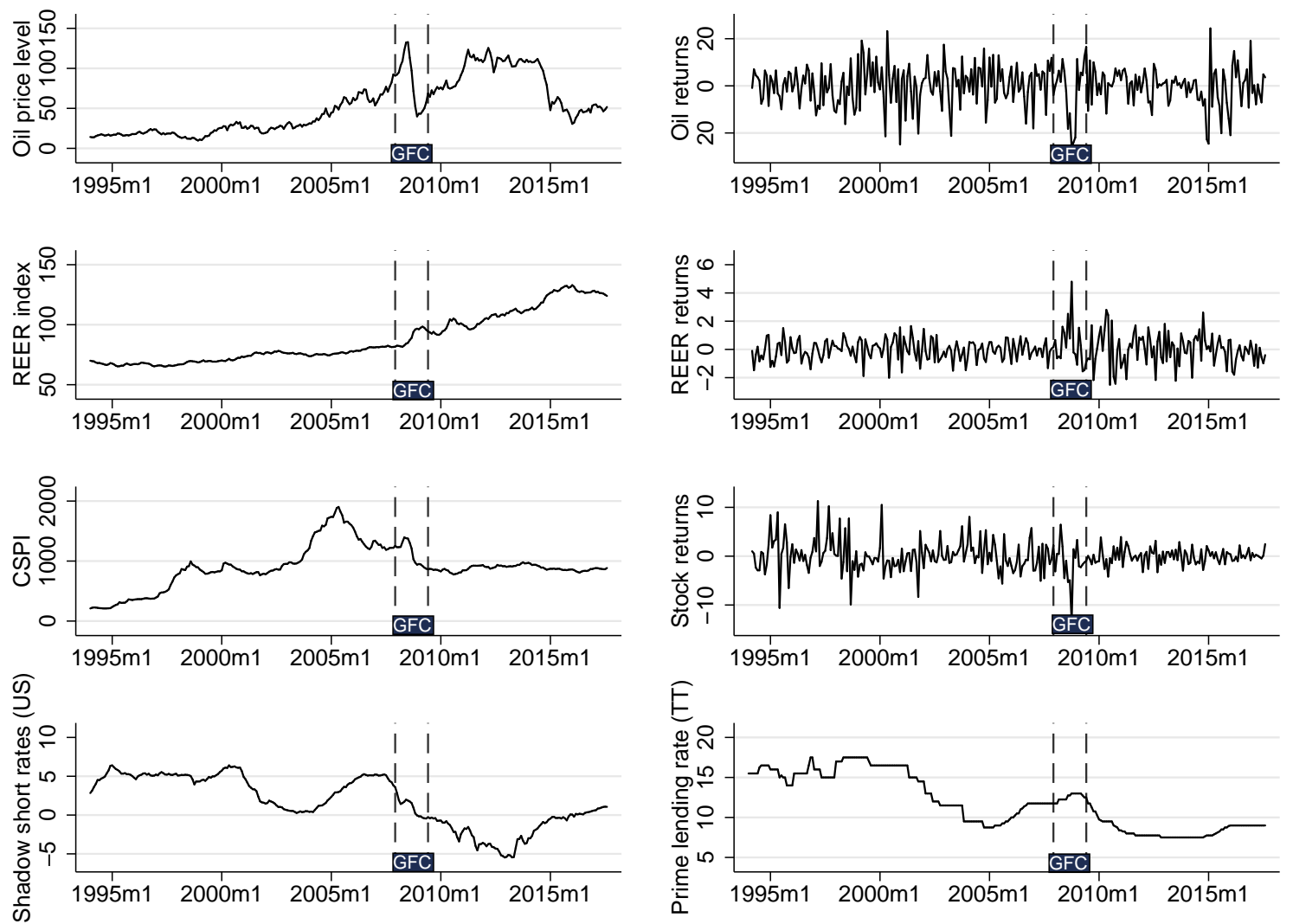

Figure 1: Monthly levels and adjusted returns of series, and foreign (US) and domestic (Trinidad and Tobago) interest rates 


\section{Results}

\subsection{Comparing the identification strategies for calm and crisis crude oil market periods}

Figure 2 shows the bear market phases of Brent crude oil prices identified by the two semi-parametric rule-based algorithms. The two approaches yield similar results with only marginal differences. Noticeably, many of the bearish trends which dominate the international crude oil market, coincide with periods of global turmoil: the Asian financial crisis (1997), the dot-com crash and the 9/11 terrorist attacks (2001), and the GFC (2008). Bearish phases are noted in the post-GFC era, the most striking of which was the sharp oil price collapse between June 2014 and January 2015. This decline is attributed, in part, to a negative oil demand shock from a slowdown in the world economy, as well as positive oil supply shocks coming from the US shale boom and other oil producers such as Canada and Russia (Baumeister and Kilian, 2016b,a).

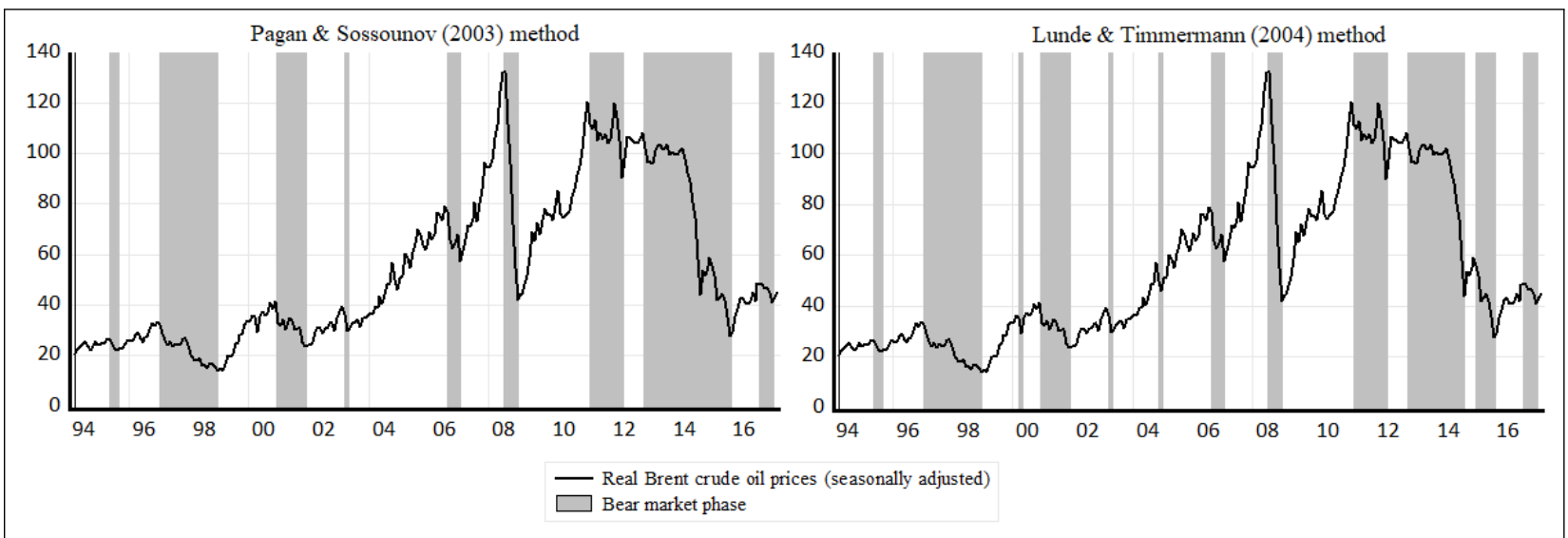

Figure 2: Energy crises based on bearish oil price phases in the Brent crude oil market

Figure 3 depicts both volatility estimates ${ }^{13}$ of Brent crude oil prices over our sample period. The realised monthly volatility is a much more volatile measure than the range estimator, where the standard deviations of former and latter are 5.03 and 1.09, respectively. This diagram also illustrates the turbulent (crisis) and tranquil (calm) classifications based on the cluster analysis of the two volatility measures. The clustering algorithm is applied to each series for the full sample and also with the GFC period censored. As such, the higher (lower) horizontal lines in each graph indicate the threshold values between the turbulent and tranquil scenarios of the full (censored) sample. These thresholds are calculated as the sum of the minimum value of the turbulent group and the maximum value of the tranquil group, divided by two.

\footnotetext{
${ }^{13}$ Scaled up by 100 for ease of interpretation.
} 


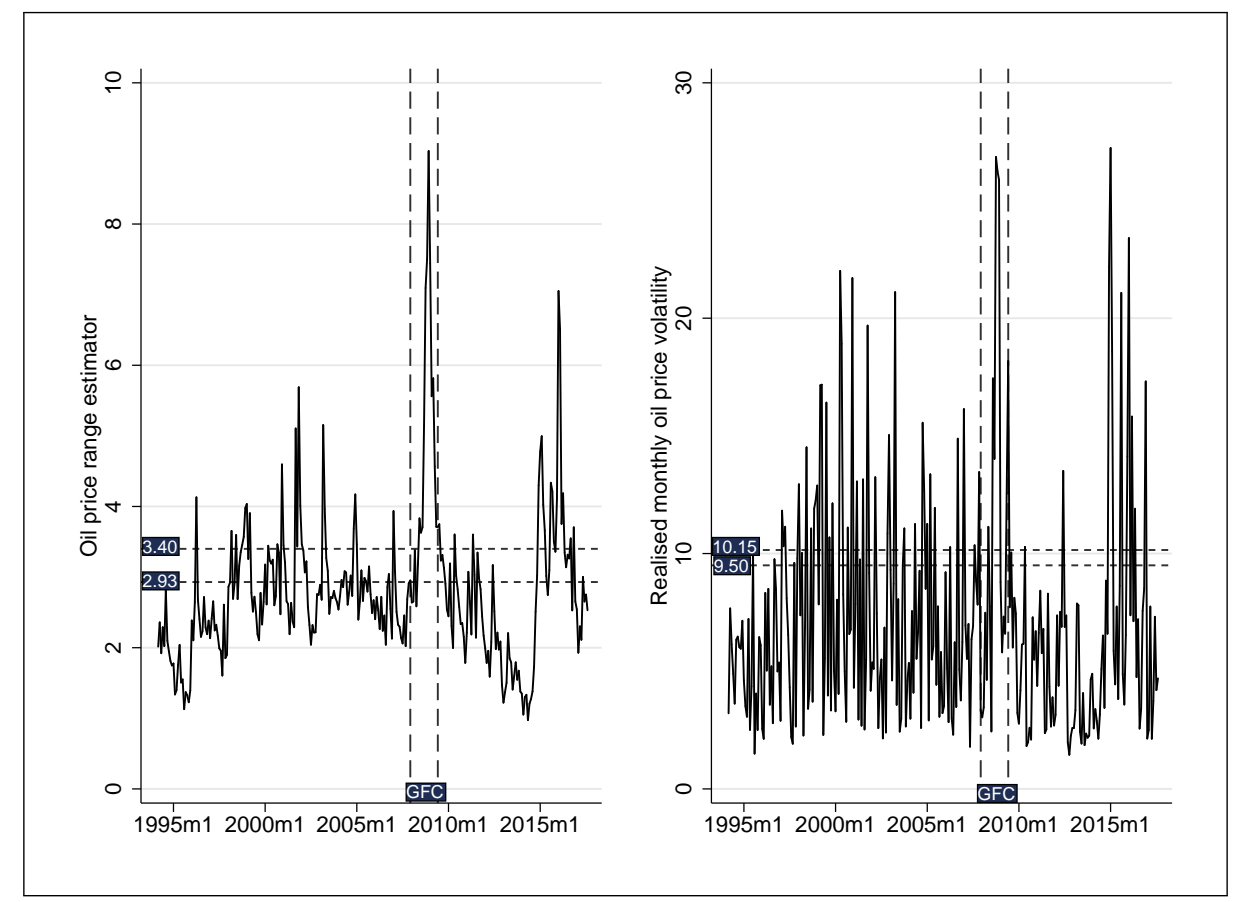

Figure 3: Energy calm/crisis classification based on Brent crude oil market volatility

It is useful to understand how the calm and crisis periods identified by the four aforementioned strategies, i.e. the two semi-parametric rule-based algorithms and the two volatility measures, are related. Nested in Table 1 are the contingency tabulations for any two identification strategies, represented as a 3 x 3 matrix. Together, these 12 matrices allow for comparisons between all four techniques in both the full and GFC-censored samples. A simple measure of similarity (dissimilarity) between two identification approaches is computed by summing the two leading (off) diagonal elements and diving by the grand total of that 3 × 3 contingency table. For example, we note a 97.16\% similarity (i.e. $((168+106) / 282) \times 100)$ between the Pagan and Sossounov (2003) (P\&S) and Lunde and Timmermann (2004) (L\&T) rule-based algorithms in the full sample. In fact, because the similarity between these two techniques is so high throughout Table 1, to avoid repetition in the results section we only report the findings using the Pagan and Sossounov (2003) method, since this is the more widely deployed method in the applied literature ${ }^{14}$.

Concerning the two volatility measures, the similarity between them in the full and GFC-censored samples were $80.14 \%$ and $69.96 \%$, respectively. Therefore, we report on both methods in the results as they appear to capture different perspectives. Furthermore, the similarity between the $\mathrm{P} \& \mathrm{~S}$ and the crude oil range estimator was $63.12 \%$ in 395 full sample and $56.65 \%$ in the GFC-censored sample, whereas the similarity between P\&S and the realised monthly average crude oil volatility was $60.28 \%$ in the full sample and $60.08 \%$ in the GFC-censored sample. This suggests that bear (bull) market phases are not clear indicators of turbulent (tranquil) volatility scenarios, providing only partial

\footnotetext{
${ }^{14}$ Our results using the Lunde and Timmermann (2004) approach can be made available upon request.
} 
evidence for leverage effects ${ }^{15}$ in the international crude oil market based on the Brent benchmark.

Table 1: Combined contingency table for measuring the similarity between the calm and crisis periods in the crude oil market across the four identification strategies, for both the full and GFC-censored samples.

\begin{tabular}{|c|c|c|c|c|c|c|c|c|c|c|c|c|c|c|c|c|c|c|c|}
\hline & & \multicolumn{9}{|c|}{ Full sample } & \multicolumn{9}{|c|}{ GFC-censored sample } \\
\hline & & \multicolumn{3}{|c|}{ L\&T } & \multicolumn{3}{|c|}{ Range est. } & \multicolumn{3}{|c|}{ Realised avg. vol. } & \multicolumn{3}{|c|}{ L\&T } & \multicolumn{3}{|c|}{ Range est. } & \multicolumn{3}{|c|}{ Realised avg. vol. } \\
\hline & & Calm & Crisis & Total & Calm & Crisis & Total & Calm & Crisis & Total & Calm & Crisis & Total & Calm & Crisis & Total & Calm & Crisis & Total \\
\hline \multirow{3}{*}{$P \& S$} & Calm & 168 & 4 & 172 & 148 & 24 & 172 & 143 & 29 & 172 & 155 & 4 & 159 & 112 & 47 & 159 & 131 & 28 & 159 \\
\hline & Crisis & 4 & 106 & 110 & 80 & 30 & 110 & 83 & 27 & 110 & 4 & 100 & 104 & 67 & 37 & 104 & 77 & 27 & 104 \\
\hline & Total & 172 & 110 & 282 & 228 & 54 & 282 & 226 & 56 & 282 & 159 & 104 & 263 & 179 & 84 & 263 & 208 & 55 & 263 \\
\hline \multirow{3}{*}{ L\&T } & Calm & & & & 148 & 24 & 172 & 144 & 28 & 172 & & & & 112 & 47 & 159 & 132 & 27 & 159 \\
\hline & Crisis & & & & 80 & 30 & 110 & 82 & 28 & 110 & & & & 67 & 37 & 104 & 76 & 28 & 104 \\
\hline & Total & & & & 228 & 54 & 282 & 226 & 56 & 282 & & & & 179 & 84 & 263 & 208 & 55 & 263 \\
\hline \multirow{3}{*}{$\begin{array}{l}\text { Range } \\
\text { est. }\end{array}$} & Calm & & & & & & & 199 & 29 & 228 & & & & & & & 154 & 25 & 179 \\
\hline & Crisis & & & & & & & 27 & 27 & 54 & & & & & & & 54 & 30 & 84 \\
\hline & Total & & & & & & & 226 & 56 & 282 & & & & & & & 208 & 55 & 263 \\
\hline
\end{tabular}

\subsection{Performance of financial returns by energy market conditions}

Table 2 presents summary statistics for the adjusted returns by energy market conditions, i.e. bullish or bearish and tranquil or turbulent scenarios. In addition, our empirical applications are performed on both the full and a GFCcensored sample to see whether the results are sensitive to the contemporary financial crash. Interestingly, we observe that the REER appreciates (depreciates) under bearish (bullish) and turbulent (tranquil) oil market conditions, suggesting that Trinidad and Tobago is more uncompetitive (competitive) in periods of crisis (calm) in the crude oil market. Moreover, in the full sample exchange rates are more volatile under bearish and turbulent oil market conditions, whereas these results are inconclusive in the GFC-censored sample, implicitly implying the rise in volatility is associated with the GFC period.

Additionally, mixed results are received concerning Trinidad and Tobago's stock market. When the crude oil market is slumping (booming), as conveyed by bearish (bullish) oil market conditions, stock returns are positive (negative). Yet, under turbulent (tranquil) oil price volatility, stock returns are falling (rising). Generally, higher stock market volatility is noted under crisis periods (both bearish and turbulent) in oil markets, compared to calm periods.

\footnotetext{
${ }^{15}$ Leverage effects imply that falling (rising) asset prices propagate higher (lower) volatility.
} 
Table 2: Descriptive statistics of adjusted returns by sample and energy conditions

\begin{tabular}{|c|c|c|c|c|c|c|c|c|c|c|c|c|c|c|}
\hline \multirow[b]{2}{*}{ Sample } & \multirow[b]{2}{*}{$\begin{array}{l}\text { Energy } \\
\text { conditions }\end{array}$} & \multirow[b]{2}{*}{ Obs. } & \multicolumn{4}{|c|}{ Real oil returns } & \multicolumn{4}{|c|}{ REER returns } & \multicolumn{4}{|c|}{ Real stock returns } \\
\hline & & & Mean & SD & Min. & Max. & Mean & SD & Min. & Max. & Mean & SD & Min. & Max. \\
\hline \multicolumn{15}{|c|}{ Bull \& Bear oil market scenarios } \\
\hline \multicolumn{15}{|c|}{ Pagan and Sossounov (2003) algorithm } \\
\hline \multirow{2}{*}{ Full } & Bullish & 172 & 2.86 & 7.15 & -21.41 & 23.22 & -0.13 & 0.93 & -2.50 & 2.80 & -0.02 & 2.64 & -6.51 & 10.51 \\
\hline & Bearish & 110 & -4.48 & 8.96 & -26.54 & 24.39 & 0.20 & 0.95 & -2.22 & 4.79 & 0.03 & 3.46 & -13.29 & 11.29 \\
\hline GFC- & Bullish & 159 & 2.64 & 7.20 & -21.41 & 23.22 & -0.13 & 0.92 & -2.50 & 2.80 & -0.02 & 2.62 & -6.51 & 10.51 \\
\hline censored & Bearish & 104 & -3.73 & 8.40 & -24.89 & 24.39 & 0.14 & 0.83 & -2.22 & 2.61 & 0.26 & 3.22 & -10.59 & 11.29 \\
\hline
\end{tabular}

\section{Volatility scenarios}

Crude oil price range estimator

\begin{tabular}{clccccccccccccc}
\multirow{2}{*}{ Full } & Tranquil & 228 & 1.08 & 6.88 & -21.41 & 23.22 & -0.03 & 0.89 & -2.50 & 2.61 & 0.16 & 2.88 & -10.59 & 11.29 \\
& Turbulent & 54 & -4.56 & 13.00 & -26.54 & 24.39 & 0.14 & 1.17 & -1.79 & 4.79 & -0.70 & 3.31 & -13.29 & 7.70 \\
\multirow{2}{*}{ GFC- } & Tranquil & 179 & 1.01 & 6.45 & -16.03 & 19.08 & -0.06 & 0.87 & -2.50 & 2.61 & 0.25 & 2.90 & -10.59 & 11.29 \\
censored & Turbulent & 84 & -1.77 & 11.07 & -24.89 & 24.39 & 0.05 & 0.95 & -2.17 & 2.80 & -0.25 & 2.78 & -9.88 & 7.72
\end{tabular}

\begin{tabular}{ccccccccccccccc}
\multicolumn{2}{l}{ Realised monthly oil price volatility } \\
\multirow{2}{*}{ Full } & Tranquil & 226 & 0.57 & 5.32 & -10.60 & 11.36 & -0.06 & 0.91 & -2.50 & 2.61 & 0.16 & 2.76 & -10.59 & 10.51 \\
& Turbulent & 56 & -2.32 & 16.15 & -26.54 & 24.39 & 0.23 & 1.08 & -1.88 & 4.79 & -0.63 & 3.69 & -13.29 & 11.29 \\
\multirow{2}{*}{ GFC- } & Tranquil & 208 & 0.43 & 5.14 & -10.60 & 10.74 & -0.05 & 0.92 & -2.50 & 2.61 & 0.14 & 2.74 & -10.59 & 10.51 \\
\multirow{2}{*}{ censored } & Turbulent & 55 & -1.05 & 15.18 & -24.89 & 24.39 & 0.08 & 0.76 & -1.88 & 2.80 & -0.08 & 3.33 & -9.88 & 11.29 \\
\hline
\end{tabular}

\subsection{Energy contagion evidence}

\subsubsection{Correlation analysis}

Table 3 shows the calm and crisis correlation coefficients using the Pearson, Spearman, and Kendall ${ }^{16}$ measures, ${ }^{415}$ for both the full and GFC-censored samples under the various calm/crisis classification methods. In the far right column, the adjusted linear correlation coefficient (i.e., $\hat{v}_{y \mid x_{i}}$ ) gives the Pearson correlation between oil and financial returns in the crisis period, corrected to accommodate for spurious increases in crisis period volatility. A relatively modest negative interdependence is observed in the crude oil-exchange rate relationship in the two samples, across all identification strategies. This implies an inverse oil-exchange rate relationship, i.e. the REER appreciates (depreciates) ${ }_{420}$ when oil prices decrease (increase). However, in the full sample, the financial relationship between crude oil and stock

\footnotetext{
${ }^{16}$ Generally, in absolute value, Kendall's $\tau$ tends to be smaller than the other two correlation measures (see also Conover (1999)).
} 
markets are negative in calm periods and positive in crisis periods; but these connections are not robust to the GFCcensored sample, which suggests the GFC period has distorting effects on the country's equities.

Table 3: Correlation coefficients during calm and crisis periods in the oil-exchange rate and oil-stock market relationships, across the different calm/crisis identification methods, for both the full and GFC-censored samples.

\begin{tabular}{|c|c|c|c|c|c|c|c|c|}
\hline \multirow{3}{*}{ Sample } & \multirow{3}{*}{$\begin{array}{l}\text { Calm/crisis } \\
\text { classification } \\
\text { method }\end{array}$} & \multicolumn{7}{|c|}{ Correlation measure } \\
\hline & & \multicolumn{2}{|c|}{ Pearson's $\rho$} & \multicolumn{2}{|c|}{ Spearman's $\rho$} & \multicolumn{2}{|c|}{ Kendall's $\tau$} & \multirow{2}{*}{$\begin{array}{l}\hat{v}_{y \mid x_{i}} \\
\text { Crisis }\end{array}$} \\
\hline & & Calm & Crisis & Calm & Crisis & Calm & Crisis & \\
\hline \multicolumn{9}{|c|}{ Oil-exchange rate relationship } \\
\hline & PS (2003) & -0.23 & -0.30 & -0.25 & -0.23 & -0.17 & -0.15 & -0.24 \\
\hline \multirow[t]{2}{*}{ Full } & Range est. & -0.27 & -0.37 & -0.31 & -0.29 & -0.20 & -0.19 & -0.20 \\
\hline & Realised vol. & -0.31 & -0.35 & -0.32 & -0.34 & -0.22 & -0.22 & -0.12 \\
\hline \multirow{3}{*}{$\begin{array}{l}\text { GFC- } \\
\text { censored }\end{array}$} & PS (2003) & -0.23 & -0.21 & -0.24 & -0.21 & -0.16 & -0.14 & -0.18 \\
\hline & Range est. & -0.30 & -0.21 & -0.34 & -0.19 & -0.22 & -0.13 & -0.12 \\
\hline & Realised vol. & -0.31 & -0.30 & -0.32 & -0.30 & -0.22 & -0.19 & -0.10 \\
\hline \multicolumn{9}{|c|}{ Oil-stock market relationship } \\
\hline & PS (2003) & -0.06 & 0.12 & -0.07 & 0.09 & -0.04 & 0.06 & 0.10 \\
\hline \multirow[t]{2}{*}{ Full } & Range est. & -0.04 & 0.08 & -0.03 & -0.04 & -0.02 & -0.03 & 0.04 \\
\hline & Realised vol. & -0.01 & 0.04 & -0.01 & -0.01 & -0.01 & 0.01 & 0.01 \\
\hline \multirow{3}{*}{$\begin{array}{l}\text { GFC- } \\
\text { censored }\end{array}$} & PS (2003) & -0.06 & 0.01 & -0.07 & 0.04 & -0.05 & 0.02 & 0.01 \\
\hline & Range est. & 0.00 & -0.13 & -0.02 & -0.12 & -0.01 & -0.09 & -0.08 \\
\hline & Realised vol. & 0.01 & -0.12 & 0.01 & -0.09 & 0.01 & -0.05 & -0.04 \\
\hline
\end{tabular}

Notes: All correlation coefficients lie between 0 and 1, where 0 implies no correlation but increases as absolute values move away from 0 with $+/$ - indicating positive/negative associations between crude oil and the returns of a given financial market. The following abbreviations apply- P\&S (2003) for Pagan and Sossounov (2003); range est. for range estimator; and realised vol. for realised volatility.

The correlation measures provide no compelling support for the transmission of energy contagion in the returns channel between oil and financial markets in the traditional sense of a notable deepening of cross-market linkages under crisis conditions. However, the sizeable reduction in the strength of the adjusted linear correlation coefficient in the oil-exchange rate dependence under the oil price volatility calm/crisis classifications, for both the full and GFC- 
censored samples, presents a case for reverse energy contagion. Furthermore, the two non-parametric correlation measures paint a similar picture for the range estimator in the GFC-censored sample. Thus, turbulent volatility conditions in crude oil markets appears to weaken the inverse oil-exchange rate association.

\subsubsection{Contagion testing}

Table 4 provides the adjusted linear correlation test statistic, $C R_{\overline{F R}}$; the two variants of the co-skewness test where, under crisis, $C S_{1}$ implies that the correlation between average crude oil returns and financial asset volatility increases and $C S_{2}$ conveys that the correlation between crude oil volatility and the average returns of a financial asset increases; and the co-volatility test statistic, $C V$. These are shown for each pair of energy-finance relationships, in both the full and GFC-censored samples, under each calm/crisis classification method. Focusing on the adjusted linear correlation test statistic, there are three statistically significant results illustrated in Table 4, all of which are associated with the oil-exchange rate relationship. However, in each of these cases, we observe reverse contagion since the correlation in the crisis period weakens substantially below the correlation in the calm period once the heteroskedasticity bias is adjusted, as given by the $C R_{\overline{F R}}$ correlation coefficients in Table 3 .

Consistent with Fry et al. (2010), there is evidence to suggest that the co-skewness correlation tests are able to reveal additional higher moment contagion channels in cases where the adjusted linear correlation approach suggests none. Co-skewness contagion occurred with weak significance using the bear/bull rule-based algorithm and moderate significance with the realised monthly crude oil volatility in the oil-exchange rate relationship, in the full sample. In either case, the results imply that mean crude oil market returns affect currency volatility in energy crisis periods. Turning to the oil-stock market relationship, in the full sample, the co-skewness contagion test conveys links between average oil returns and stock market volatility across all identification strategies, as well as oil market volatility and average stock returns under the bear/bull classification.

Considering the co-volatility channel, under the Pagan and Sossounov (2003) energy conditions in the full sample, there are contagion effects from oil market volatility to both exchange rate and equity volatilities. We also observe weak evidence of this contagion channel under the range estimator in the oil-exchange rate relationship, also in the full sample.

In totality, we only find evidence of energy contagion associated with the full sample. Once the GFC period has been censored, we by and large fail to reject the null hypothesis of no contagion. As such, this implicitly implies that the contagion effects noted in the full returns sample are likely a result of GFC spillovers. Thus, we observe minimal ${ }_{455}$ support for energy contagion in financial markets of this small-island energy economy. 
Table 4: Test statistics for the adjusted linear correlation $\left(C R_{\overline{F R}}\right)$, co-skewness $\left(C S_{1}\right.$ and $\left.C S_{2}\right)$, and co-volatility $(C V)$ energy contagion tests, in the oil-exchange rate and oil-stock market relationships, across the different calm/crisis identification methods, for both the full and GFC-censored samples.

\begin{tabular}{clcccccccc}
\hline \multirow{2}{*}{ Sample } & $\begin{array}{l}\text { Identification } \\
\text { method }\end{array}$ & \multicolumn{3}{c}{ Oil-exchange rate relationship } & \multicolumn{3}{c}{ Oil-stock market relationship } \\
\cline { 2 - 10 } & & $C R_{\overline{F R}}$ & $C S_{1}$ & $C S_{2}$ & $C V$ & $C R_{\overline{F R}}$ & $C S_{1}$ & $C S_{2}$ & $C V$ \\
\hline \multirow{2}{*}{ Full } & P\&S (2003) & 0.010 & $3.549^{*}$ & 0.028 & $8.499^{* * *}$ & 2.215 & $3.974^{* *}$ & $4.055^{* *}$ & $8.620^{* * *}$ \\
& Range est. & 0.450 & 2.498 & 0.018 & $3.404^{*}$ & 0.783 & $12.439^{* * *}$ & 0.261 & 2.335 \\
& Realised vol. & $6.291^{* *}$ & $4.605^{* *}$ & 0.395 & 1.919 & 0.130 & $3.413^{*}$ & 0.389 & 0.328 \\
& & & & & & & & & \\
\multirow{2}{*}{ GFC- } & P\&S (2003) & 0.164 & 2.118 & 0.959 & 1.797 & 0.376 & 0.111 & 1.384 & 0.238 \\
censored & Range est. & $3.668^{*}$ & 0.317 & 0.031 & 0.159 & 0.579 & 0.546 & 1.418 & 0.649 \\
& Realised vol. & $7.186^{* * *}$ & 0.187 & 0.422 & 0.004 & 0.380 & 0.694 & 0.132 & 0.078 \\
\hline
\end{tabular}

Notes: $* * *, * *$, and $*$ denote the conventional $1 \%$ (strong), $5 \%$ (moderate), and $10 \%$ (weak) levels of statistical significance, respectively, which corresponds to $\chi_{1}^{2}$ critical values of $6.635,3.841$, and 2.706 for the $C R_{\overline{F R}}, C S_{1}, C S_{2}$, and $C V$ contagion tests. Additionally, all abbreviations used in the identification method column, are the same as described in Table 3.

\section{Policy implications}

The increased uncompetitiveness of Trinidad and Tobago, as indicated by the appreciation (depreciation) of the REER when crude oil markets are in crisis (calm) periods, along with negative correlation between exchange rate and oil returns across all energy market conditions, are surprising artefacts for a small open energy-intensive economy. Indeed, the positive wealth effect channel and Dutch disease conjecture suggests the opposite, i.e. oil booms are associated with exchange rate appreciations. In fact, our results for Trinidad and Tobago are more consistent with oil-importing countries ${ }^{17}$ and we attribute this to the de facto exchange rate regime, which anchors the Trinidad and Tobago dollar to the US dollar. A natural concern is whether such an exchange rate policy is appropriate for this small-island energy economy. From the standpoint of our analysis, the current currency stabilisation arrangement appears sufficient for the following reasons. Firstly, given that both the theoretical and empirical literature generally find a negative link between oil prices and the US dollar exchange rate (Wu et al., 2012; Reboredo et al., 2014), for some oil-exporting emerging economies with currencies tied to the US dollar, part of the gains (losses) arising from oil price increases (decreases) are absorbed by the depreciation (appreciation) of the US dollar and such a currency peg provides the potential to taper the influence of oil price volatility on the purchasing power (Reboredo, 2012).

\footnotetext{
${ }^{17}$ For example, see Lizardo and Mollick (2010) for Japan and Ghosh (2011) for India.
} 
Furthermore, if the existence of a positive association between oil prices and the REER is indeed a requisite for the Dutch disease (Mironov and Petronevich, 2015), then our finding of an inverse oil-exchange rate relationship implies that the managed float buffers Trinidad and Tobago from this infection. Although our contagion analyses are based on returns and do not take into account the long run behaviour of these variables, we argue that this short run outlook is appropriate for Dutch disease diagnostics. The Dutch disease is an acute, not chronic, problem with no inhibiting long run macroeconomic growth consequences for resource-rich economies (Kojo, 2015). In the presence of a boom, any potential exchange rate appreciation will occur in the short run, but this is merely a transitory equilibrium, which dissipates as the time horizon expands (van der Ploeg, 2011). As such, the Dutch disease is relevant to countries that have experienced unanticipated exogenous shocks of foreign income derived from a natural resource discovery that is not expected to endure, and is less applicable to countries where a natural resource is the apex commodity and has been for a relatively long time (Mohaddes and Pesaran, 2013).

Additionally, in small island states characterised by high export concentration and a limited range of internationally competitive tradeable goods, it may be tempting to argue for the devaluation of the currency to promote export-led growth. However, the mechanical outlook that depreciations are perceived to improve the international competitiveness of a country, by making exports relatively cheaper and imports more expensive, while appreciations do the opposite, is dogmatic as it does not take into account the import content of exports (Abeysinghe and Yeok, 1998) and may be impractical for the small open economy whose size does not permit them to reasonably displace imports (Worrell et al., 2018). This is confirmed by provisional data for 2017 which shows that $37.50 \%$ of the total value of imports in Trinidad and Tobago consisted of energy commodities (CBTT, 2018), which were likely destined to be refined for exportation.

Turning to the oil-stock market linkages, given that stock price volatility can be used as an indicator for the uncertainty faced by the firms quoted on that market (Lee et al., 2011), then our finding of higher standard deviations in stock returns under energy crisis conditions suggests a rise in investment uncertainty in such times. However, from the correlation and contagion analyses, the weak relationship between the crude oil market and equities in Trinidad and Tobago is consistent with the findings of Basher et al. (2018) regarding the inconsequential role played by oil prices in the Mexican stock market, which is also an oil-exporter with no substantial energy commodities traded on the stock exchange. Yet, this current dependence structure is likely to change if more energy-related securities are traded on the stock market of such countries. For Trinidad and Tobago, while the relatively new ${ }^{18}$ and only energy security listed on the TTSE consists of about $2.06 \%$ of the market capitalisation for the First Tier Market (TTSE, 2017), an additional public offering of approximately USD 125.40 million was put forward in 2017 bringing the market capitalisation contribution of this security to around $2.50 \%$ (TTSE, 2018). Therefore, it will be interesting to see how the oil-stock market relationship evolves in this environment if further public offerings are made by this company, or more energy firms pursue equity financing and commence trading on the TTSE.

\footnotetext{
${ }^{18}$ The initial public offering of the only energy security traded on the TTSE occurred in the last quarter of 2015 (TTSE, 2016).
} 
For TTSE to benefit from oil price increases as other oil-exporters have, and to build up resilience when such the moment, the regional environment in which the TTSE operates pose unique challenges which can potentially inhibit spillover benefits from the energy and real sectors to financial markets. In the Caribbean region, even the more advanced stock markets like the TTSE are still embryonic in comparison to those of advanced economies; these stock exchanges are too illiquid to be an appealing option for some investors; the local business community in Trinidad and Tobago has a culture which favours commercial bank credit over equity financing; there is a reluctance to dilute family ownership and publicly disclose company information; the general public has a risk averse culture; and financial illiteracy concerning investment options is pervasive (see Cozier and Watson (2018) and references therein). To complement the ongoing national financial literacy initiatives in Trinidad and Tobago, we endorse the policy prescriptions of Cozier and Watson (2018), which includes: The divestment of state enterprises, especially energy sector holdings, onto the TTSE; fiscal incentives, like tax moratoriums for companies that are quoted on the TTSE and tax relief for individuals who invest in these; and forging further strategic alliances with more developed financial markets to increase investment options.

\section{Conclusion}

We make three original contributions to the current energy-finance literature. First, we put forward the novel concept of energy contagion, i.e. a strengthening of energy-finance relationships during crisis periods in energy markets. Energy contagion analysis is pertinent for academic research, policy formulation, and investment decisions centred on how developments in the international crude oil market affect the macroeconomic and financial environment of commodity exporters and importers.

Second, we introduce tests for energy contagion using crude oil as the source market. To detect energy contagion across various co-moment transmission channels, we define the calm and crisis sub-samples of correlation, co-skewness, and co-volatility contagion tests based on energy, instead of financial, market conditions. Two types of calm/crisis identification methods are used to determine calm and crisis scenarios in the crude oil market: semiparametric rule-based algorithms for detecting bull and bear oil price phases, which proxies booms and slumps in oil prices; and a non-hierarchical k-means clustering algorithm to sort volatility measures into discrete episodes of tranquil and turbulent volatility.

Third, we address a gap in the literature by applying our analysis to the small open petroleum-exporting economy of Trinidad and Tobago. Not only is this country an appropriate study site for our analysis but it is one where published studies on the energy-finance nexus are, to the best of our knowledge, virtually non-existent. We test the aforementioned co-moment transmission channels for energy contagion in the crude oil-exchange rate and crude oilstock market relationships to better understand the ramifications of oil market crises on financial stability in the setting of this small and heavily petroleum-dependent economy. 
Our results for Trinidad and Tobago show an inverse correlation between oil and real effective exchange rate returns. Although the literature suggests the opposite result for an oil-exporting country, we attribute this empirical peculiarity to the domestic currency peg to the US dollar. We also find weak correlation between oil and stock returns. This insensitivity is likely due to the embryonic local equity market. While we observe the transmission of energy contagion through multiple co-moment channels, these occur only during the contemporary global financial crisis. Altogether, the results provide unique insights into the relationship between international oil prices and key financial variables in this small petroleum economy.

\section{Acknowledgements}

Earlier versions of this paper were presented in Paris at the $6^{\text {th }}$ International Symposium on Environment and Energy Finance Issues in May 2018, and in Milan at the $11^{\text {th }}$ International Workshop on Empirical Methods in Energy Economics held in June 2018. We are grateful to the participants of these conferences for their useful comments. We also thank Jim Steeley and the anonymous reviewers for their helpful suggestions. The usual disclaimer applies. This research did not receive any specific grant from funding agencies in the public, commercial, or not-for-profit sectors. 


\section{Appendix A. Data Appendix}

Table A.5: Data definitions and sources

\begin{tabular}{|c|c|c|}
\hline Series & Definition & Source \\
\hline Real Oil Prices (OP) & $\begin{array}{l}\text { European Brent crude oil spot prices expressed in constant } 2010 \text { USD, using } \\
\text { the consumer price index on all items for the United States. }\end{array}$ & $\begin{array}{l}\text { Calculated using Federal Reserve } \\
\text { Economic Data (FRED) }\end{array}$ \\
\hline Interest Rates (IR) & $\begin{array}{l}\text { Trinidad and Tobago's commercial banking median basic prime lending } \\
\text { rate. }\end{array}$ & $\begin{array}{l}\text { The Central Bank of Trinidad and } \\
\text { Tobago (CBTT) }\end{array}$ \\
\hline $\begin{array}{l}\text { Real Composite Stock } \\
\text { Price Index (CSPI) }\end{array}$ & $\begin{array}{l}\text { A market-value weighted index collectively measuring the price movement } \\
\text { of the ordinary shares for companies listed on the First Tier market of the } \\
\text { Trinidad and Tobago Stock Exchange, delimited in a base year of 1983, } \\
\text { adjusted for inflation using the retail price index on all items with a base } \\
\text { year of } 2010 .\end{array}$ & $\begin{array}{l}\text { Calculated using data from the } \\
\text { Central Bank of Trinidad and } \\
\text { Tobago (CBTT) }\end{array}$ \\
\hline $\begin{array}{l}\text { Real Effective Exchange } \\
\text { Rates (REER) }\end{array}$ & $\begin{array}{l}\text { Trinidad and Tobago's Nominal Effective Exchange Rate (NEER) adjusted } \\
\text { for inflation using the local } 2010 \text { retail price index, where the NEER is a } \\
\text { measure of the value of a currency against a weighted average of several } \\
\text { foreign currencies. }\end{array}$ & $\begin{array}{l}\text { International Monetary Fund (IMF) } \\
\text { International Financial Statistics }\end{array}$ \\
\hline $\begin{array}{l}\text { Shadow Short Rates } \\
\text { (SSR) }\end{array}$ & $\begin{array}{l}\text { SSR is the shortest maturity rate from the estimated shadow yield curve in } \\
\text { the United States. This policy interest rate can take on negative values to } \\
\text { reflect unconventional monetary policy during the contemporary quantitative } \\
\text { easing era in the United States (see Krippner (2016)). }\end{array}$ & $\begin{array}{l}\text { Leo Krippner, Research programme, } \\
\text { Reserve Bank of New Zealand. }\end{array}$ \\
\hline
\end{tabular}

Note: All data were retrieved between March and May 2018.

\section{References}

Abdullah, M. B., 1990. On a robust correlation coefficient. The Statistician, 455-460.

Abeysinghe, T., 2001. Estimation of direct and indirect impact of oil price on growth. Economics Letters 73 (2), 147-153.

Abeysinghe, T., Yeok, T. L., 1998. Exchange rate appreciation and export competitiveness. The case of Singapore. Applied Economics 30 (1),

Algieri, B., Leccadito, A., 2017. Assessing contagion risk from energy and non-energy commodity markets. Energy Economics 62, 312-322.

Aloui, R., Hammoudeh, S., Nguyen, D. K., 2013. A time-varying copula approach to oil and stock market dependence: The case of transition economies. Energy Economics 39, 208-221.

Auty, R. M., 2017. Natural resources and small island economies: Mauritius and Trinidad and Tobago. The Journal of Development Studies 53 (2),

264-277.

Baruník, J., Kočenda, E., 2018. Total, asymmetric and frequency connectedness between oil and forex markets. arXiv preprint arXiv:1805.03980. Basher, S. A., Haug, A. A., Sadorsky, P., 2016. The impact of oil shocks on exchange rates: A Markov-switching approach. Energy Economics 54, $11-23$. 
Basher, S. A., Haug, A. A., Sadorsky, P., 2018. The impact of oil-market shocks on stock returns in major oil-exporting countries. Journal of International Money and Finance 86, $264-280$.

Bastianin, A., Conti, F., Manera, M., 2016. The impacts of oil price shocks on stock market volatility: Evidence from the G7 countries. Energy Policy 98, 160-169.

Baumeister, C., Kilian, L., 2016a. Forty years of oil price fluctuations: Why the price of oil may still surprise us. Journal of Economic Perspectives 30 (1), 139-60.

Baumeister, C., Kilian, L., 2016b. Understanding the decline in the price of oil since June 2014. Journal of the Association of Environmental and Resource Economists 3 (1), 131-158.

Baumeister, C., Peersman, G., 2013. The role of time-varying price elasticities in accounting for volatility changes in the crude oil market. Journal of Applied Econometrics 28 (7), 1087-1109.

Bjørnland, H. C., 2004. The role of the exchange rate as a shock absorber in a small open economy. Open Economies Review 15 (1), $23-43$.

Bjørnland, H. C., 2009. Oil price shocks and stock market booms in an oil exporting country. Scottish Journal of Political Economy 56 (2), $232-254 . \quad 575$ CBTT, 2009. Economic Bulletin. Tech. Rep. July, Central Bank of Trinidad and Tobago (CBTT).

CBTT, 2015. Economic Bulletin. Tech. Rep. July, Central Bank of Trinidad and Tobago (CBTT).

CBTT, 2018. Annual Economic Survey 2017. Tech. rep., Central Bank of Trinidad and Tobago (CBTT).

Chang, C.-Y., Lai, J.-Y., Chuang, I.-Y., 2010. Futures hedging effectiveness under the segmentation of bear/bull energy markets. Energy Economics 32 (2), 442-449.

Chiang, T. C., Jeon, B. N., Li, H., 2007. Dynamic correlation analysis of financial contagion: Evidence from Asian markets. Journal of International Money and Finance 26 (7), 1206-1228.

Chkili, W., Nguyen, D. K., 2014. Exchange rate movements and stock market returns in a regime-switching environment: Evidence for BRICS countries. Research in International Business and Finance 31, 46-56.

Cleveland, R. B., Cleveland, W. S., Terpenning, I., 1990. Stl: A seasonal-trend decomposition procedure based on loess. Journal of Official Statistics $6(1), 3$.

Conover, W., 1999. Practical nonparametric statistics. Wiley Series in Probability and Statistics: Applied Probability and Statistics. Wiley.

Corden, W. M., 1984. Booming sector and Dutch disease economics: Survey and consolidation. Oxford Economic Papers 36 (3), 359-380.

Corden, W. M., 2012. Dutch disease in Australia: Policy options for a three-speed economy. Australian Economic Review 45 (3), $290-304$.

Cozier, J. G., Watson, P. K., 2018. The evolution of stock markets in the CARICOM region (1969-2010): Lessons for other small emerging 590 economies. Handbook of Small States: Economic, Social and Environmental Issues.

Creti, A., Joëts, M., Mignon, V., 2013. On the links between stock and commodity markets' volatility. Energy Economics 37, 16-28.

Diaz, E. M., Molero, J. C., de Gracia, F. P., 2016. Oil price volatility and stock returns in the G7 economies. Energy Economics 54, 417-430.

Diebold, F. X., Yilmaz, K., 2009. Measuring financial asset return and volatility spillovers, with application to global equity markets. The Economic Journal 119 (534), 158-171.

Diebold, F. X., Yilmaz, K., 2014. On the network topology of variance decompositions: Measuring the connectedness of financial firms. Journal of Econometrics $182(1), 119-134$.

Ding, Z., Liu, Z., Zhang, Y., Long, R., 2017. The contagion effect of international crude oil price fluctuations on Chinese stock market investor sentiment. Applied Energy 187, 27-36

Downey, M., 2009. Oil 101. Wooden Table Press.

Elder, J., Serletis, A., 2011. Volatility in oil prices and manufacturing activity: An investigation of real options. Macroeconomic Dynamics 15 (S3), 379-395.

Forbes, K. J., Rigobon, R., 2002. No contagion, only interdependence: Measuring stock market comovements. The Journal of Finance 57 (5), 2223-2261.

Fry, R., Martin, V. L., Tang, C., 2010. A new class of tests of contagion with applications. Journal of Business \& Economic Statistics 28 (3), 605 $423-437$. 
Fry-McKibbin, R., Hsiao, C. Y.-L., 2018. Extremal dependence tests for contagion. Econometric Reviews 37 (6), 626-649.

Fry-McKibbin, R., Hsiao, C. Y.-L., Tang, C., 2014. Contagion and global financial crises: lessons from nine crisis episodes. Open Economies Review 25 (3), 521-570.

Gelb, A. H., 1988. Oil windfalls: Blessing or curse? Oxford University Press.

Ghosh, S., 2011. Examining crude oil price-exchange rate nexus for India during the period of extreme oil price volatility. Applied Energy 88 (5), 1886-1889.

Gil-Alana, L. A., Gupta, R., Olubusoye, O. E., Yaya, O. S., 2016. Time series analysis of persistence in crude oil price volatility across bull and bear regimes. Energy 109, 29-37.

Gogineni, S., 2010. Oil and the stock market: An industry level analysis. Financial Review 45 (4), 995-1010.

Guo, F., Chen, C. R., Huang, Y. S., 2011. Markets contagion during financial crisis: A regime-switching approach. International Review of Economics \& Finance 20 (1), 95-109.

Hamilton, J. D., 1996. This is what happened to the oil price-macroeconomy relationship. Journal of Monetary Economics 38 (2), 215 - 220.

Hamilton, J. D., 2003. What is an oil shock? Journal of Econometrics 113 (2), 363-398.

Huang, R. D., Masulis, R. W., Stoll, H. R., 1996. Energy shocks and financial markets. Journal of Futures Markets: Futures, Options, and Other Derivative Products $16(1), 1-27$.

Inci, A. C., Li, H.-C., McCarthy, J., 2011. Financial contagion: A local correlation analysis. Research in International Business and Finance 25 (1), 11-25.

Jiménez-Rodríguez, R., 2015. Oil price shocks and stock markets: Testing for non-linearity. Empirical Economics 48 (3), $1079-1102$.

Jones, C. M., Kaul, G., 1996. Oil and the stock markets. The Journal of Finance 51 (2), 463-491.

Kayalar, D. E., Küçüközmen, C. C., Selcuk-Kestel, A. S., 2017. The impact of crude oil prices on financial market indicators: Copula approach. Energy Economics 61, 162-173.

Kilian, L., 2016. The impact of the shale oil revolution on US oil and gasoline prices. Review of Environmental Economics and Policy 10 (2), $185-205$.

Kilian, L., Zhou, X., 2018. Oil prices, exchange rates and interest rates. Unpublished.

Kojo, N. C., 2015. Demystifying Dutch disease. Journal of International Commerce, Economics and Policy 6 (02), 1550010.

Kole, E., Dijk, D., 2017. How to identify and forecast bull and bear markets? Journal of Applied Econometrics 32 (1), $120-139$.

Korhonen, I., Juurikkala, T., 2009. Equilibrium exchange rates in oil-exporting countries. Journal of Economics and Finance 33 (1), $71-79$.

Krippner, L., 2016. Documentation for measures of monetary policy. Reserve Bank of New Zealand. Wellington, New Zealand.

Lee, K., Kang, W., Ratti, R. A., 2011. Oil price shocks, firm uncertainty, and investment. Macroeconomic Dynamics 15 (S3), $416-436$.

Lee, K., Ni, S., Ratti, R. A., 1995. Oil shocks and the macroeconomy: The role of price variability. The Energy Journal, 39-56.

Li, F., Zhu, H., 2014. Testing for financial contagion based on a nonparametric measure of the cross-market correlation. Review of Financial Economics 23 (3), 141-147.

Lizardo, R. A., Mollick, A. V., 2010. Oil price fluctuations and US dollar exchange rates. Energy Economics 32 (2), $399-408$.

Lunde, A., Timmermann, A., 2004. Duration dependence in stock prices: An analysis of bull and bear markets. Journal of Business \& Economic Statistics 22 (3), 253-273.

Mironov, V. V., Petronevich, A. V., 2015. Discovering the signs of Dutch disease in Russia. Resources Policy 46, $97-112$.

Mohaddes, K., Pesaran, M. H., 2013. One hundred years of oil income and the Iranian economy: A curse or a blessing? In: Iran and the Global Economy. Routledge, pp. 28-61.

Mohanty, S. K., Nandha, M., Turkistani, A. Q., Alaitani, M. Y., 2011. Oil price movements and stock market returns: Evidence from Gulf Cooperation Council (GCC) countries. Global Finance Journal 22 (1), 42-55.

Mork, K. A., 1989. Oil and the macroeconomy when prices go up and down: An extension of Hamilton's results. Journal of Political Economy 97 (3), 740-744

Ntantamis, C., Zhou, J., 2015. Bull and bear markets in commodity prices and commodity stocks: Is there a relation? Resources Policy 43, 61-81. 
Pagan, A. R., Sossounov, K. A., 2003. A simple framework for analysing bull and bear markets. Journal of Applied Econometrics 18 (1), $23-46$.

Papapetrou, E., 2001. Oil price shocks, stock market, economic activity and employment in Greece. Energy Economics 23 (5), $511-532$.

Parkinson, M., 1980. The extreme value method for estimating the variance of the rate of return. Journal of Business, 61-65.

Reboredo, J. C., 2011. How do crude oil prices co-move?: A copula approach. Energy Economics 33 (5), 948-955.

Reboredo, J. C., 2012. Modelling oil price and exchange rate co-movements. Journal of Policy Modeling 34 (3), 419-440.

Reboredo, J. C., Rivera-Castro, M. A., 2013. A wavelet decomposition approach to crude oil price and exchange rate dependence. Economic Modelling 32, 42-57.

Reboredo, J. C., Rivera-Castro, M. A., Zebende, G. F., 2014. Oil and US dollar exchange rate dependence: A detrended cross-correlation approach. Energy Economics 42, 132 - 139.

Sadorsky, P., 1999. Oil price shocks and stock market activity. Energy Economics 21 (5), 449-469.

Samuel, W., Viseth, A., 2018. Monetary transmission mechanisms in selected small island developing states with floating exchange rates. Handbook of Small States: Economic, Social and Environmental Issues.

Serletis, A., Xu, L., 2018. The zero lower bound and crude oil and financial markets spillovers. Macroeconomic Dynamics 22 (03), $654-665$.

TTSE, 2006. Annual Report 2005. Tech. rep., Trinidad and Tobago Stock Exchange (TTSE) Limited.

TTSE, 2016. Annual Report 2015. Tech. rep., Trinidad and Tobago Stock Exchange (TTSE) Limited.

TTSE, 2017. Annual Report 2016. Tech. rep., Trinidad and Tobago Stock Exchange (TTSE) Limited.

TTSE, 2018. Annual Report 2017. Tech. rep., Trinidad and Tobago Stock Exchange (TTSE) Limited.

Turhan, M. I., Sensoy, A., Hacihasanoglu, E., 2014. A comparative analysis of the dynamic relationship between oil prices and exchange rates. Journal of International Financial Markets, Institutions and Money 32, 397-414.

van der Ploeg, F., 2011. Natural resources: Curse or blessing? Journal of Economic Literature 49 (2), 366-420.

Wang, Y., Wu, C., Yang, L., 2013. Oil price shocks and stock market activities: Evidence from oil-importing and oil-exporting countries. Journal of Comparative Economics 41 (4), 1220-1239.

WEC, 2016. World energy resources 2016. Tech. rep., World Energy Council (WEC).

Wen, X., Wei, Y., Huang, D., 2012. Measuring contagion between energy market and stock market during financial crisis: A copula approach. Energy Economics 34 (5), 1435 - 1446.

Worrell, D., Moore, W., Beckles, J., 2018. A new approach to exchange rate management in small open financially integrated economies. In: Briguglio, L. (Ed.), Handbook of Small States: Economic, Social and Environmental Issues. Routledge.

Wu, C.-C., Chung, H., Chang, Y.-H., 2012. The economic value of co-movement between oil price and exchange rate using copula-based GARCH models. Energy Economics 34 (1), 270-282.

Yang, L., Cai, X. J., Hamori, S., 2017. Does the crude oil price influence the exchange rates of oil-importing and oil-exporting countries differently? A wavelet coherence analysis. International Review of Economics \& Finance 49, 536-547.

Zhang, D., Broadstock, D. C., 2018. Global financial crisis and rising connectedness in the international commodity markets. International Review of Financial Analysis, Forthcoming.

Zhang, Y.-J., Fan, Y., Tsai, H.-T., Wei, Y.-M., 2008. Spillover effect of US dollar exchange rate on oil prices. Journal of Policy Modeling 30 (6), 973-991. 